\title{
Reston: A plastic surgeon's dream material
}

\author{
Hugh G Thomson MD MS FRCSC FACS
}

HG Thomson. Reston: A plastic surgeon's dream material. Can J Plast Surg 2002;10(2):89-91.

Reston foam is a polyurethane ether polymer that has many attractive features for use by plastic surgeons. In the present paper, these features are addressed and clinical examples are shown.

\section{Reston : Une matière de rêve pour le plasticien}

La mousse Reston est une polymère d'éther de polyuréthane dotée de nombreuses caractéristiques intéressantes pour le plasticien. Dans le présent article, ces caractéristiques sont passées en revue, et des exemples cliniques sont présentés.

Key Words: Polyurethane foam; Reston

$\mathrm{T}$ he major difference between perfection and 'just good' is frequently a trifle. Plastic surgeons pride themselves in the use of specialized 'things' to provide excellent results. Reston (3M, Canada) foam is one such trifling thing! As Dr Hoyle Campbell said frequently during my residency, "If you are faced with a unique surgical need, solve this need by trotting out a customized trick from your sleeve!" Reston is truly one of those tricks!

Reston was introduced to the North American market in 1963 by 3M (Minnesota Mining Manufacturing Company, Canada). It has many remarkable physical features that make it an exciting product for plastic surgeons to use in addressing specific practice challenges.

\section{PHYSICAL CHARACTERISTICS}

The physical characteristics of Reston foam are as follows.

- Reston is a polyurethane ether foam with an adhesive backing. It can be used with or without the easily removable backing.

- Reston can be gas autoclaved without physical change. For this, the foam is packaged in a peel bag that can remain on the shelf indefinitely.

- Fire prevention precautions are not necessary in the use of Reston foam. 
- Hazardous depolymerization does not occur in Reston; therefore, no first aid precautions are necessary.

- Reston's hypoallergenic adhesive backing does not lose its tenacity after sterilization.

- Mild skin irritation can occur after prolonged and repeated contact with Reston.

- A normal waste disposal technique is all that is required to dispose of Reston.

- 3M advises that Reston should not be used for "any off-label uses."

\section{CLINICAL APPLICATIONS}

Some of the many clinical uses of Reston foam are as follows.

- The compressible nature of the foam and its adhesive backing make it an excellent interface for skin protection during positioning of anesthesia tubing.

- Eye protection after the removal of the adhesive backing that faces outwards away from the eye.

- Skin grafts can be randomly meshed with a \#11 blade by stretching the skin graft on top of Reston's unremoved adhesive backing.

- Custom fitting of the foam is done by carving with a scalpel, which makes the foam available for unlimited contouring, such as for use in modelling congenital ear deformities.

- The Reston foam can be stapled and/or sutured for skin graft pressure dressing, particularly if its adhesive backing is left in place.

- Reston foam does not fracture when penetrated with a K-wire or suture needle.

- Reston foam serves as an ideal compression dressing in difficult regions because it will move with the patient and the area of the anatomy that is involved without causing any shearing.

- Reston foam is relatively inexpensive. The cost of a $20 \times 30 \mathrm{~cm}$ sheet is $\$ 2.68$.

The major reported application of this product has been as a compression dressing for skin grafts (1-6). There have been other uses, however, such as preoperative shaping of congenital ear deformities (7), postoperative compression after liposuction (8), preoperative molding dressings in microtia reconstruction (9) and prevention of pressure sores (10).

There are many other clinical applications of this versatile product. For example, it can be used as a specialized
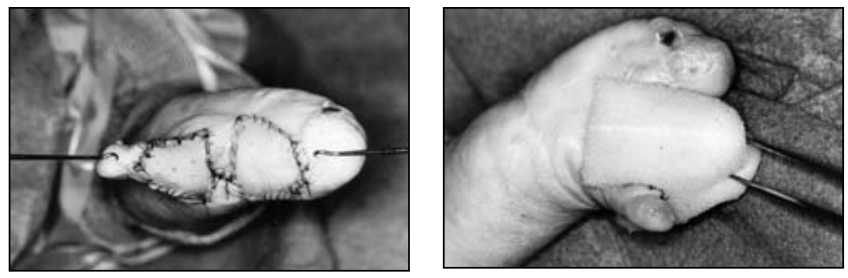

Figure 1) Left Individualized burn thumb-index syndactyly. Full thickness skin grafts with fine random meshing; ready for foam dressing application. Right Reston (3M, Canada) folded on itself and ' $V$ ' contoured to fit well up into syndactylized area. Over-tie bolster sutures would then be inserted
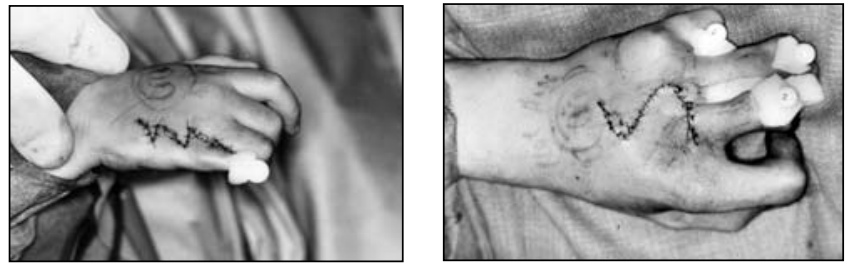

Figure 2) Left Under polydactyly with amputation and closure; Kwire fixation, finger tip protected with Reston (3M, Canada), 'happy face' logo for recognition of operative site. Right Tendon transfer in arthrogryposis to mid-ring-little fingers. Three tips protected from ball and K-wire with Reston. Intertriginous maceration prevention between mid and ring fingers by using oblong strips of Reston foam
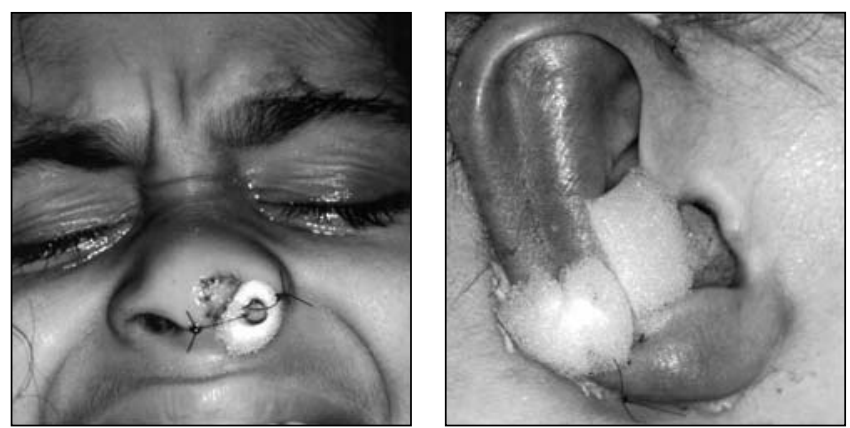

Figure 3) Left Nasal stenosis release with free composite ear graft; stent of polyethylene tubing clothed with wrap-around adhesive, Reston (3M, Canada). Right Set-back otoplasty with through-and-through bolster sutures in antihelix over Reston foam

contour dressing for syndactyly, in which carving a specialized shape and stay suture insertion is necessary. The double thickness of the foam can be obtained by folding it on itself by making use of the adhesive backing (Figure 1). The Reston foam protects the fingertip skin from potential pressure necrosis due to the $\mathrm{K}$-wire and ball after an osteotomy or fracture (Figure 2). The adhesive backing of the sponge can be incorporated on an appropriate sized polyethylene stent when traumatic nasal stenosis is released with a free composite ear graft and is sutured in place (Figure 3, left). Also, through-and-through suture bolsters are protected by using Reston to prevent additional skin injury during the swelling stage of a set-back otoplasty (Figure 3, right).

\section{CONCLUSION}

The uses for this product are almost unlimited, depending on how big your 'sleeve' and need are. 


\section{REFERENCES}

1. Harris D. A new technique of skin grafting using Steri-Greffe and a self adhering foam pad. Br J Plast Surg 1981;34:181-5.

2. Markison RD, Colville J. Adhesive foam technique for rapid simple skin grafting. Surg Gyn Obstet 1983;157:276-8.

3. Weiner LJ, Moberg AW. An ideal stent for reliable and efficient skin graft application. Ann Plast Surg 1984;13:24-8.

4. Larson PO. Foam rubber stents for skin grafts. J Dermatol Surg Oncol 1990;16:851-4.

5. Wells MD. A new method of skin graft stabilization: the Reston technique. Ann Plast Surg 1995;34:554-6.
6. Saltz R, Bowles BJ. Reston: an alternate method of skin graft fixation. Plast Reconstr Surg 1997;99:601-2. (Lett)

7. Kurozumi N, Ono S, Ishida H. Non-surgical correction of a congenital lop ear deformity by splinting with Reston foam. Br J Plast Surg 1982;35:181-2.

8. Schlesinger SL, Kaczynski AJ. Use of Reston foam in liposuction. Aesthet Plast Surg 1993;17:49-51.

9. Ogino Y. Total reconstruction of the auricle in unilateral microtia. Cong Anom 1984;24:429-38.

10. Hughes AW. Prevention of pressure sores in patients with fractures of the femoral neck. Injury 1986;17:19-22.

\section{ERRATUM}

In the paper "Use of Dermagraft in the treatment of acute traumatic wounds" by Deckert et al (Can J Plast Surg 2002;10[Suppl A]:31A-35A), Figure 9 was printed incorrectly. The figure, as it should have appeared, is printed below. Our apologies are extended to the authors.

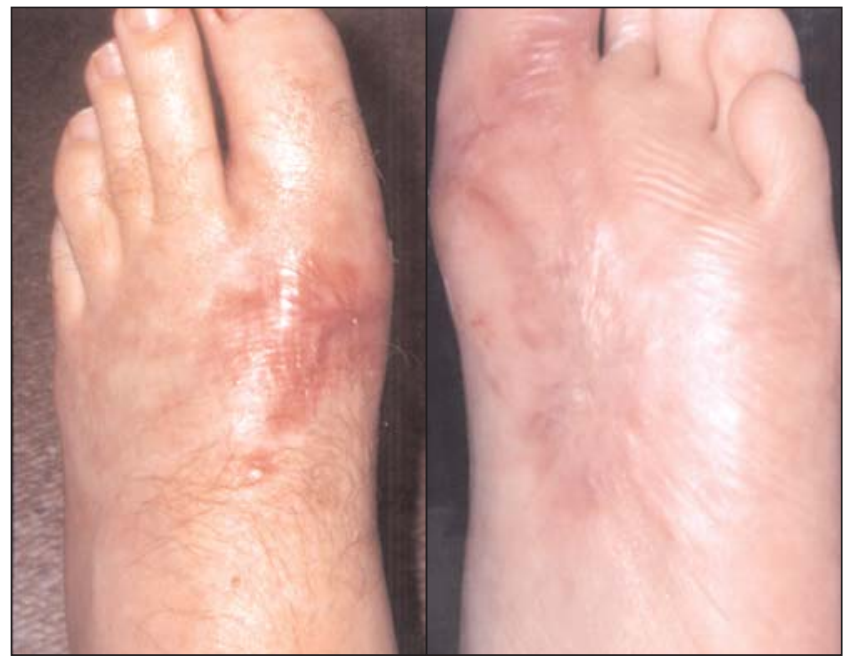

Figure 9) The patient's foot on February 21, 2001 - 58 days after wound closure. Note: April 3, 2002: The wound has remained closed since this photograph. The patient applies moisturizing lotion to the area on a daily basis. He reports ongoing improvement in the tensile strength of the tissue 